1 Universidad de El Salvador - San Salvador, El Salvador. eduardo@espinoza.ca

2 Universidad Internacional por la Salud de los Pueblos (IPHU) - San Salvador, EI

Salvador.

${ }^{3}$ Asociación

Latinoamericana de

Medicina Social y Salud

Colectiva (Alames) -

Buenos Aires, Argentina.

\section{David Sanders, un compañero de lucha extraordinario}

\author{
David Sanders, an extraordinary partner for all struggles
}

Eduardo Espinoza', $\mathbf{1 , 2}$

DOI: $10.1590 / 0103-110420205120$

DAVID SANDERS FUE UNA DE LAS PERSONAS CON MAYOR LUCIDEZ y mejor visión de Salud Pública que he conocido. Reunía características especiales que a todas luces le colocaban en primera fila para conducir los destinos y el accionar de una organización como la Organización Mundial de la Salud (OMS), usurpada y cooptada por fuerzas oscuras en detrimento de su noble misión en pro de la salud de la población mundial. Creo que uno de los errores que siempre lamentaremos fue el no haber tenido la fuerza y el empuje necesarios para rescatar a la OMS de los intereses corporativos y ponerla en sus manos para llevar adelante la difícil tarea de reencauzarla hacia su compromiso con la salud de la humanidad.

Desde Halfdan Mahler no había surgido una personalidad con la fuerza, la presencia, la elocuencia, la capacidad de convocatoria y convencimiento y el poder para entusiasmar y alinear a otras personas con el liderazgo requerido en los países, a fin de dar un nuevo sentido a las políticas públicas mundiales y devolver la esperanza a la humanidad.

David Sanders acumulaba sobradamente estas características y además contaba con una sólida formación científica, una trayectoria impecable como académico e investigador y además con una amplia experiencia en el diseño e implantación de ideas innovadoras, no solo en África del Sur sino en todas las regiones y países donde su pensamiento y su activismo por el ejercicio pleno del derecho a la salud, se hacía sentir a través del accionar de sus discípulos que año con año, aplicaban con entusiasmo a sus cursos desde todo el continente Africano para tener el honor de poder escuchar sus ideas revolucionarias sobre la Atención Primaria de Salud (APS) y ponerlas en práctica al regresar a sus países de origen.

La dimensión continental de su figura, capacidad y liderazgo, dio un salto impresionante con su aporte a la idea original, el diseño y la puesta en práctica en Bangladesh de la Primera Asamblea Mundial por la Salud de los Pueblos. Su capacidad de gestión para movilizar recursos de todo tipo, el dinamismo y eficiencia que imprimió a todas las actividades preparatorias, su capacidad organizativa y su identificación plena con los objetivos superiores de luchar denodadamente por una auténtica salud para toda la humanidad, junto al esfuerzo conjunto de otro equipo visionario de figuras relevantes de la salud pública internacional, le hicieron destacar como el líder indiscutible y más relevante de este proceso.

Fue en esta primera Asamblea Mundial por la Salud de los Pueblos, en el año 2000, que conocí a David Sanders.

La guerra civil en El Salvador que se había librado durante 20 años había llegado a su fin y 
de haberse firmado los Acuerdos de Paz en 1992, quienes nos habíamos incorporado a las fuerzas revolucionarias motivados por la exclusión, las inequidades, el abandono, la persecución y la muerte con que la oligarquía local se mantenía a sangre y fuego en el poder, continuábamos nuestra lucha desde diferentes trincheras en la sociedad civil, la academia, las organizaciones populares y otras. Nuestra experiencia sanitaria durante la guerra nos llevó rápidamente a buscar y encontrar en la Atención Primaria de Salud las herramientas ideológicas y el sustento técnico-científico que requeríamos para enfrentar las fuerzas oligárquicas que en el nuevo contexto propugnaban por profundizar las inequidades en salud y el abandono de lo público para enriquecerse a costa de la privatización, la insalubridad y la muerte.

Fue así que con apoyo de la Comisión Europea realizamos en Guatemala, Nicaragua y El Salvador un trabajo investigativo de largo aliento durante cuatro años de la postguerra inmediata, el proyecto 'Rescate', así llamado porque pretendía rescatar experiencias de APS generadas por la población en las áreas de mayor conflictividad2,3. Giovanni Salazar en Guatemala, René Pérez y Gladys Ricarte en Nicaragua, Françoise Barten desde Holanda, Pol de Vos desde Bélgica, Angelita Elías y yo en El Salvador concluimos este trabajo en 2000, que culminó con un encuentro centroamericano en Managua y una declaración 'La Carta de Managua'4 en noviembre de 2000, la cual fue un importante insumo para la primera Asamblea Mundial por la Salud de los Pueblos.

Junto con Françoise Barten, nos dimos cita en la sede del evento, donde al siguiente día de mi llegada me sorprendió que llegara a buscarme un personaje que se identificó como uno de los organizadores para pedirme que, representando a Latinoamérica, formara parte de un panel en el cual representantes de los pueblos de los diferentes continentes debían interpelar a Richard Skolnic, representante del Banco Mundial, que había aceptado la invitación del Comité Organizador para asistir a la Asamblea.
El personaje en cuestión no era otro más que David Sanders. De estatura mediana, con barba y bigote poblados, de hablar pausado, firme y convincente, replicó rápidamente mis temores y dificultades que expresé para asumir tan delicada tarea. Me sorprendió como sus argumentos más contundentes los reforzaba con nuestras propias tesis y conclusiones en el proyecto Rescate. David demolió rápidamente y con contundencia mis argumentaciones para negarme a participar, su elocuencia y su ordenamiento lógico me convencieron para aplicarme a formular una declaración. Hice una traducción que revisó y corrigió Françoise y el panel fue todo un éxito. Los más de 1,000 asistentes aplaudieron todas y cada una de las intervenciones de los integrantes del panel y el representante del Banco Mundial no pudo rebatir nuestras acusaciones y reclamos por la responsabilidad del Banco y otros organismos financieros en el incumplimiento de la meta 'Salud para Todos en el año 2000'.

Luego, las siguientes Asambleas en Cuenca, Ecuador en Julio de 2005; en Ciudad del Cabo, Sudáfrica en Julio de 2012 y en Bangladesh en noviembre de 2018 fueron escenarios de otros tantos encuentros. También nos encontramos en diversos eventos en los que coincidíamos convocados por nuestra común afinidad a la defensa del derecho a la salud y a la pertinencia y validez científica de la APS: Cursos de la Universidad Internacional para la Salud de los Pueblos, asambleas regionales, eventos de investigación en salud pública y muchos otros. Poco a poco estos encuentros contribuyeron a que forjáramos una estrecha amistad y a que intercambiáramos periódicamente opiniones sobre diferentes tópicos relacionados con los factores que afectaban a la salud mundial.

Fue quizás por ello que cuando el Frente Farabundo Martí para la Liberación Nacional (FMLN), el ex frente guerrillero salvadoreño, convertido en partido político llegó al gobierno en 2009, le invitamos a visitarnos y darnos su aporte en el diseño de la Reforma de Salud ${ }^{5}$ que pretendíamos llevar adelante en el país. No dudó en aceptar y en hacernos conciencia 
especialmente sobre la idea de formar una masa crítica de activistas por el derecho a la salud que contribuyeran a llevar adelante una reforma de la envergadura y con los objetivos que nos planteábamos.

Siempre estuvo pendiente de los avances de nuestra reforma lo que inquiría cuanta vez nos encontrábamos retando nuestra imaginación con sus críticas solidarias, su humor habitual y sus fraternos consejos.

La última vez que le vi fue en Bangladesh en noviembre de 2018 durante la Cuarta Asamblea Mundial para la Salud de los Pueblos. Intercambiamos presentaciones y trabajos, lo que habíamos convertido en un hábito cada vez que nos encontrábamos y tuvimos una larga charla sobre la situación política en la que había devenido El Salvador, reiterando su impresión (que coincidía con la nuestra) de que era consecuencia entre otros factores del distanciamiento de la dirigencia política con el movimiento social, particularmente con el movimiento social en salud.

Como dije al inicio, desde Halfdan Mahler no contábamos con tantas y tan excepcionales cualidades concentradas en una sola persona, situación que hacía que atesorara cada vez más su amistad, sus conocimientos y sus capacidades

Su sensibilidad ante el sufrimiento humano solo era superada por su indignación ante la injusticia; su excelencia como investigador y docente era de tanta calidad como su oratoria y la contundencia de sus argumentos contra quienes abogaban por la privatización y la manipulación de los intereses de las mayorías.
El temor que inspiraba a los poderosos y a los burócratas que lucraban con la salud, solo era comparable a la admiración que le tenían sus discípulos y sus colegas en los nichos académicos. Su lucha en defensa de la vida y por el acceso a la salud son su más grande $\mathrm{y}$ trascendental legado a quienes tenemos la obligación moral y militante de recoger su estafeta y hacerla avanzar a niveles superiores y nuevas realizaciones.

David Sanders nos dejó cuando más necesario era su pensamiento y su capacidad de conducción; sin embargo, su inteligencia, su ejemplo y su entrega a la causa de la justicia social y el derecho a la salud deberán ser un motivo de inspiración y de continuidad en la lucha por esos nobles ideales. Eso es lo que él hubiera querido y es lo menos que podemos hacer en su memoria.

No hay duda de que la humanidad entera adquirió con este gigante de la Salud Pública una deuda que aún no alcanzamos a estimar. Es, indudablemente, una pérdida irreparable para quienes le conocimos, compartimos y trabajamos con él. Lo es también para todos los excluidos, los pobres y los marginados a quienes dedicó su vida y su trabajo.

¿Que la madre tierra, a la que tanto quiso, le sea leve y le acoja generosamente en su seno! ¡Amandla Ngawethu!

\section{Colaborador}

Espinoza E (0000-0002-4894-2924)* es responsable de redactar el manuscrito. 


\section{Referencias}

1. Barten F, Espinoza E. Rescue of Local Experiences in El Salvador and Nicaragua for the Health Sector Reform Process. European Commission Contract Holders'Meeting, Cambridge: Downing College; 1998 (Programa INCO-DEV; Contract number IC18*CT960058).

2. Dubón MA, Menjívar D, Espinoza EA, et al. Construction of the community health system in Guarjila: systematization of an experience of Comprehensive Primary Health Care in El Salvador in the period 19872007. Saúde debate. 2012; 36(94):414-420.

3. Espinoza EA. El Sistema local de Salud (SILOS) de la Zona Norte de San Salvador 1992-1997: Una experiencia innovadora en salud. [tesis].San Salvador: Facultad de Medicina, Universidad de El Salvador; 2000.
4. Universidad Nacional Autónoma de Nicaragua.“Carta de Managua" presentada el 24 de noviembre de 2000 en el Centro de Investigaciones y Estudios de la Salud de la Universidad Nacional Autónoma de Nicaragua (CIES-UNAN) en el evento preparatorio para Centroamérica de la Primera Asamblea Mundial de la Salud de los Pueblos. Managua: UNAN; 2000.

5. El Salvador. Ministerio de Salud. Política Nacional de Salud 2009-2014 "Construyendo la Esperanza”, Ministerio de Salud de El Salvador. San Salvador, Diario Oficial, Tomo 386, n. 33, p. 13-40, Feb 17/2010. [acceso en 2019 dec 20]. Disponible en: http://asp.salud.gob. sv/regulacion/pdf/derogados/Politica_nacional_de_ Salud.pdf. 